\title{
POTENTIAL EFFECT OF CLIMATE CHANGE ON TERRESTRIAL BIOTA
}

CROWLEY, Thomas J., Applied Research Corporation, 305 Arguello Drive, College Station, TX 77840 U.S.A.

There are several important changes in Phanerozoic climates that may have influenced terrestrial biota. Prior to the time of the terrestrial invasion in the early Paleozoic, an unvegetated landscape would have been associated with a larger seasonal cycle and decreased precipitation. Albedo and transpiration changes associated with the first appearance of plants should have changed this pattern, reducing the seasonal cycle and increasing precipitation. Enhanced soil weathering associated with vegetation should also have lowered atmospheric $\mathrm{CO}_{2}$ levels. During Pangaea time the giant landmass should again have caused very large seasonal cycles and decreased precipitation. Climate models invariably simulate below-freezing temperatures in winter on the supercontinent, a result at variance with inferred "equable" climates of the Jurassic. The large landmass should also have had very large Milankovitch variations. Seasonal warming during precession halfcycles of 10,000 years duration may have been associated with intermittent occupation of high-latitude sites that could bias interpretation of warmth in high latitudes. During the later Mesozoic (140-80 Ma) $\mathrm{CO}_{2}$ levels may have been several times higher than present. High $\mathrm{CO}_{2}$ levels should have affected the cycles of temperature and precipitation on land and also affected plants through the $\mathrm{CO}_{2}$ fertilization pathway. Subsequent decreased $\mathrm{CO}_{2}$ levels and continued breakup of landmasses may have influenced location of tropical rainbelts and perhaps the distribution of tropical rainforests. Numerous studies indicate that these changes, combined with expanded ice cover in the later Cenozoic, resulted in increasingly drier conditions in higher latitude land areas. The situation in the tropics is more uncertain, because there are conflicting signals from the marine realm as to the Cenozoic history of tropical sea-surface temperatures (SSTs). If early Cenozoic SSTs were in fact low (as indicated by some $\delta^{18} \mathrm{O}$ records), then tropical temperature and moisture levels may not have been high enough to sustain tropical rainforests. This summary highlights some of the excellent opportunities for interactions between paleontologists and paleoclimatologists in assessing the effects of climate change on terrestrial biota. 